\title{
Association of fever and severe clinical course in bronchiolitis
}

\author{
A Sahib El-Radhi, William Barry, Swatee Patel
}

\begin{abstract}
Little attention has been given to the relation between fever and the severity of bronchiolitis. Therefore, the relation between fever and the clinical course of 90 infants ( 59 boys, 31 girls) hospitalised during one season with bronchiolitis was studied prospectively. Fever (defined as a single recording $>38.0^{\circ} \mathrm{C}$ or two successive recording $>37.8^{\circ} \mathrm{C}$ ) was present in 28 infants. These infants were older (mean age, $5.3 v$ 4.0 months), had a longer mean hospital stay (4.2 $v 2.7$ days), and a more severe clinical course $(71.0 \% v 29.0 \%)$ than those infants without fever. Radiological abnormalities (collapse/consolidation) were found in $60.7 \%$ of the febrile group compared with $14.8 \%$ of the afebrile infants. These results suggest that monitoring of body temperature is important in bronchiolitis and that fever is likely to be associated with a more severe clinical course and radiological abnormalities.

(Arch Dis Child 1999;81:231-234)
\end{abstract}

Keywords: fever; bronchiolitis; disease severity

Bronchiolitis is a major cause of lower respiratory tract infection in infancy. Most children have had respiratory syncytial virus (RSV) infection by the age of 2 years. ${ }^{1}{ }^{2}$ Pre-existing chronic lung disease, congenital heart disease, immunodeficiency, prematurity, parental smoking, and infection in very early infancy predispose to severe illness and occasional death..$^{3-5}$ Apnoea or respiratory arrest before hospitalisation and pulmonary consolidation on chest $x$ ray have been associated with increased morbidity. ${ }^{6}$ A greater disease severity has been reported in group A RSV than group $\mathrm{B}$ infection.

There are few reports of the incidence of fever in bronchiolitis, or its relation to the severity of the disease or radiological findings; furthermore, any such reports have produced conflicting results. Fever has been variously described as being very common in the initial phase of the illness, but largely disappearing by the time of hospitalisation ${ }^{8}$; as a characteristic feature of the disease ${ }^{9}$; as intermittent and rarely exceeding $38-39^{\circ} \mathrm{C}^{10}$; or as a sign rarely exceeding $38^{\circ} \mathrm{C} .{ }^{11}$ These studies have merely stated the incidence of fever but we are not aware of the evidence underlying these conclusions. Those few studies that have investigated the incidence of fever in bronchiolitis have involved small numbers of children. A Swedish study $^{12}$ of 15 infants with RSV infection reported fever in 14 . Another study ${ }^{13}$ reported an incidence of fever as low as $12 \%$ among 25 infants aged less than 3 months with RSV infection. In addition, this study found that all six children with bronchiolitis caused by parainfluenza virus were afebrile.

Information on the relation between fever and clinical severity is even more limited. A single report ${ }^{14}$ on the clinical findings and severity of bronchiolitis showed that respiratory rate on admission, chest wall indrawing, temperature, heart rate, and liver displacement did not predict the severity of the infection. However, of the six clinical signs studied to predict oxygen requirements, fever was not included. More information is required to determine whether there is an association between the severity of bronchiolitis and fever.

Our study was carried out to assess the extent of fever in bronchiolitis, whether the clinical course differs between febrile and afebrile infants with bronchiolitis, and whether fever in bronchiolitis is beneficial or harmful.

Patients and methods

All infants aged over 1 month who were admitted to Queen Mary's Hospital, Sidcup, UK during one season with a diagnosis of acute bronchiolitis were studied prospectively. $\mathrm{Pa}-$ tients were admitted between November 1997 and February 1998. In our hospital, between 80 and 120 infants are admitted with the disease each winter. The diagnosis of bronchiolitis was made in the presence of a history of upper respiratory tract infection followed by acute onset of respiratory distress with cough, breathlessness, and wheeze, and clinical signs of chest overinflation, tachypnoea, rhonchi, or crepitations occurring during a winter epidemic of bronchiolitis. ${ }^{15}$ Only children with their first episode of broncholitis were included.

The timing of discharge was based on the establishment of a normal feeding pattern without an oxygen requirement and absence of fever, in accordance with our usual practice.

The severity of the infection was assessed using a simple severity index as described by McIntosh et al. ${ }^{16}$ This index takes the requirement of oxygen to be the best single initial measurement of the severity of the illness in bronchiolitis. Infants who required mechanical ventilation were classified as very severe, those who required oxygen supplement as severe, and those who required admission for observation without oxygen requirement as mild.

The axillary temperature was recorded on admission and monitored at least four hourly. Fever was defined as a single temperature recording $>38^{\circ} \mathrm{C}$ or two successive 
Table 1 Clinical data of 90 children with bronchiolitis

\begin{tabular}{|c|c|c|c|c|c|c|}
\hline \multirow[b]{2}{*}{ Groups } & \multirow{2}{*}{$\begin{array}{l}\text { Mean age in } \\
\text { months (range) }\end{array}$} & \multirow{2}{*}{$\begin{array}{l}\text { Mean length of stay } \\
\text { in days (range) }\end{array}$} & \multicolumn{2}{|c|}{ Clinical severity } & \multicolumn{2}{|c|}{$\begin{array}{l}\text { Radiological changes } \\
\text { (segmental/lobar } \\
\text { collapse/consolidation) }\end{array}$} \\
\hline & & & Severe (\%) & Mild (\%) & Normal (\%) & Abnormal (\%) \\
\hline Febrile $(\mathrm{n}=28)$ & $5.3(1-10.25)$ & $4.2(1-13)$ & $20(71.4)$ & $8(28.6)$ & $11(39.3)$ & $17(60.7)$ \\
\hline Afebrile $(n=62)$ & $4.0(1-11.75)$ & $2.7(1-10)$ & $18^{\star}(29)$ & $44(71)$ & $52(85.2)$ & $9(14.8)$ \\
\hline $\mathrm{p}$ Value & 0.033 & $<0.005$ & $<0.005$ & & $<0.005$ & \\
\hline
\end{tabular}

* One child had a very severe clinical course (ventilated) in the afebrile group.

temperature recordings $>37.8^{\circ} \mathrm{C}$, taken four hours apart during the first 24 hours of admission.

All children underwent examination of the nasopharyngeal aspirates for RSV and had a chest $x$ ray. RSV was detected using Directigen RSV (Becton Dickinson, Oxford, UK) kits. Results were given as positive, negative, or uninterpretable and, in the latter case, a repeat measurement was carried out using an appropriate dilution. The RSV antigen was the only virus tested for.

A chest $x$ ray was taken either on admission or within the first 24 hours of admission, and some $x$ rays were repeated in cases of clinical deterioration. All $x$ rays were reported upon by a radiologist for review after the discharge of the infants. The radiologist was unaware of the clinical severity or body temperature, but aware of the clinical diagnosis. The films were examined for the presence of hyperinflation and its degree, peribronchial streaky infiltration, and segmental/lobar collapse, with or without consolidation.

All children were managed according to a routine protocol, which included isolation in cubicles, continuous monitoring of oxygen saturation by pulse oximetry, and the provision of supplemental oxygen if required to maintain oxygen saturation $>92 \%$. Breast milk or formula milk was offered if tolerated, with appropriate volume for age. Children not tolerating oral feeds because of dyspnoea, or those with severe bronchiolitis at presentation, received intravenous fluid and/or milk via a nasogastric tube. Nebulised ipratropium bromide was often prescribed as a trial and continued in those who responded. Antibiotics were administered if there was radiological evidence of collapse/consolidation and to those children who appeared toxic.

The $t$ test (unrelated) and $\chi^{2}$ test were used for statistical analysis.

\section{Results}

Ninety infants ( 59 boys, 31 girls) with a mean age of 4.4 months (SD, 2.7; range, 1-11.75) were studied. The duration of their illness from onset of coryzal symptoms until admission ranged between one and 13 days. The duration of their stay in hospital ranged from one to 10 days, with a mean of 3.1 days (SD, 1.9). A history of fever was present in 25 children and this information was obtained from the parents. RSV was identified from the nasopharyngeal aspirates in 55 of the 90 children tested.

The children were divided into two groups according to body temperature: febrile and
Table 2 Ranges of body temperature in 28 febrile children

\begin{tabular}{lc}
\hline Body temperature $\left({ }^{\circ} \mathrm{C}\right)$ & Children $(n)$ \\
\hline$<38.0$ & 1 \\
$<39.0$ & 16 \\
$<40.0$ & 9 \\
$\geqslant 40.0$ & 2 \\
Total & 28 \\
\hline
\end{tabular}

afebrile. Table 1 shows the clinical data and results of radiological abnormalities. The mean age of the febrile group was significantly higher than that of the afebrile group ( $p=0.033 ; 95 \%$ confidence intervals (CI), 0.1 to 2.5 ). The mean length of hospital stay was significantly higher in the febrile group (4.2 $v 2.7$ days; $\mathrm{p}<0.005 ; 95 \% \mathrm{CI}, 0.7$ to 2.3 ). A significantly higher disease severity was seen in the febrile group $(71.0 \%)$ compared with the afebrile group $(29.0 \%$; $<<0.005)$. One child was classified as having very severe disease in the afebrile group. No deaths occurred. Thirteen infants were born prematurely, four in the febrile group and nine in the afebrile group. Similar proportional results were obtained from RSV testing in the febrile and afebrile groups. There was no known case with underlying cardiac or pulmonary disease or immunodeficiency.

There were 28 febrile children, with most body temperature measurements ranging between $38^{\circ} \mathrm{C}$ and $39^{\circ} \mathrm{C}$ (table 2). Eighteen children had a history of fever in association with an upper respiratory tract infection before admission. Children with a body temperature $>39^{\circ} \mathrm{C}(\mathrm{n}=17)$ tended to be older, had a similar mean duration of stay in hospital, and had similar clinical severity, although they were more likely to have radiological abnormalities compared with those with a body temperature $<39^{\circ} \mathrm{C}(\mathrm{p}=0.066)$. The mean duration of fever was 2.2 days (range, $0.5-5$; SD, 1.3).

Overall, 20 of the 28 febrile children had a severe clinical score.

The remaining 62 children were afebrile on admission and remained so throughout their hospital stay. A history of fever before admission was obtained from seven of these infants. Only one child had a very severe clinical course and required ventilation for two days. He made a full recovery.

Because the radiological changes of collapse and consolidation are virtually indistinguishable, ${ }^{11}$ both were grouped together (table 1). The incidence of segmental/lobar collapse/consolidation was significantly higher in the febrile group than in the afebrile group. 


\section{Discussion}

The mean age of the population studied was 4.4 months, which is similar to that reported elsewhere, indicating that bronchiolitis mainly affects infants aged 2-5 months. ${ }^{17}$ The mean length of hospitalisation of 3.3 days is, however, significantly shorter than that reported from several hospitals in Canada (8.6-11.8 days), ${ }^{18}$ but is closer to that reported from Manchester, UK (4.5 days). ${ }^{19}$ Local variability influencing the pattern and severity of RSV infection, and thus the length of hospitalisation, has been reported. ${ }^{20}$

One of the limitations of our study was virological testing for RSV only. It would have been interesting to investigate differences in the incidence of fever and disease severity among other viruses that cause bronchiolitis, such as influenza and parainfluenza viruses, adenoviruses, and rhinoviruses. As previously noted, one study ${ }^{13}$ found that all six children with bronchiolitis caused by parainfluenza virus were afebrile.

Dual infection with other viruses, such as adenoviruses, or organisms such as Chlamydia trachomatis or Mycoplasma pneumoniae, is common and has been found in at least $5-10 \%$ of cases of lower respiratory tract infection infected with RSV. ${ }^{21} 22$

The main objective of our report was to study the clinical sign of fever in children with bronchiolitis. Fever is the most common sign of infectious diseases. Studies are needed to determine in specific paediatric diseases whether fever alone is beneficial, harmful, or without effect. In some diseases-for example, salmonella gastroenteritis, the presence of fever was associated with a shorter duration of convalescent faecal bacterial excretion than was seen in afebrile children. ${ }^{23}$ Children with high fever at the onset of the initial febrile convulsion had a significantly decreased recurrence rate compared with those with lower temperatures. ${ }^{24}$ Therefore, fever appears to have a favourable prognostic value in some diseases. The findings of our study suggest that most infants with bronchiolitis are afebrile $(69 \%)$ and that fever is associated with more severe bronchiolitis.

In respiratory diseases, particularly those occurring in young infants, such as bronchiolitis, hypoxia is common and may be severe. In our series, 38 of the 90 children had severe bronchiolitis requiring supplemental oxygen to maintain adequate oxygen saturation. A rise in body temperature results in an increase in energy expenditure of about $10 \%$ for each $1^{\circ} \mathrm{C}$ rise in temperature. These changes are accompanied by an increase in oxygen consumption of $10-12 \%$ for every $1{ }^{\circ} \mathrm{C}$ rise in temperature..$^{25}$ This may explain why a high proportion of the febrile children (20 of 28) had a severe clinical course of bronchiolitis requiring oxygen supplementation. The necessity for oxygen supplementation was one of the main factors contributing to prolonged hospitalisation. It is possible that a reduction of body temperature by frequent use of antipyretic agents could reduce the oxygen requirement and possibly the degree of hypoxia.
Fever in respiratory diseases can increase the rate of pre-existing tachycardia and tachypnoea, which are caused by the disease itself. ${ }^{26}$ Therefore, tachycardia and tachypnoea may not be reliable signs of disease severity in febrile infants. Hence, oxygen saturation and the need for oxygen supplement were taken as criteria of disease severity. Furthermore, some infants with less severe bronchiolitis, who would not initially require oxygen supplementation, may do so later because of additional tachycardia and tachypnoea as a result of fever.

The presence of segmental/lobar collapse with consolidation in most of the febrile children might also have caused both a febrile response and a severe clinical course requiring an increase in oxygen consumption. Because many children with a severe clinical course were afebrile $(29 \%)$ and had a normal chest $x$ ray, fever and radiological abnormalities do not seem to be the only factors contributing to clinical severity. Although some reports ${ }^{6} 1727$ suggested a correlation between radiological abnormalities on a chest $x$ ray and disease severity, others ${ }^{28}$ could not confirm such a correlation. Fever, however, was not studied in these reports. Our study suggests that there is a correlation between disease severity and radiological changes in both febrile and afebrile children. Because febrile children had a higher incidence of such severity, more radiological abnormalities were expected in this group.

In contrast to other studies, ${ }^{2629}$ which reported that children with bronchiolitis younger than 3 months of age have a more severe clinical course, in our study, the mean age of children with greater disease severity was higher than those with milder disease. Fever was, however, not included in these studies. In our study, children with a severe presentation within the same febrile or afebrile group were actually younger than those with a mild presentation (data not shown).

The reason why most of the 90 children were afebrile is not entirely clear. Production of interferon is enhanced as an important defence mechanism in many respiratory viral infections, including bronchiolitis. Interferon is known to be a potent endogenous pyrogen capable of inducing fever. However, the production of interferon by blood mononuclear cells has been shown to be significantly reduced during acute RSV bronchiolitis. ${ }^{30}$ This may explain the low incidence of fever in bronchiolitis. In addition, infants below the age of 3 months are less likely than older children to mount a febrile response, despite severe infection, because they have an immature thermoregulatory system and a lower metabolic rate than older children. ${ }^{31}$

We thank Dr Kensit and his team from the microbiology department, Queen Mary's Hospital, Sidcup, for their assistance in processing the nasopharyngeal aspirates from the studied children. We also thank the nursing staff on the Whiteoak Ward for their help during the study.

1 Henderson FW, Collier AM, Clyde WA, et al. Respiratory syncytial virus infections, reinfections, and immunity. $N$ syncytial virus infections, re
Engl f Med 1979;300:530-4.

2 Lebel MH, Gauthier M, Lacroix J, et al. Respiratory failure and mechanical ventilation in severe bronchiolitis. Arch Dis Child 1989;64:1431-7. 
3 Webb MSC, Reynold LJ. Management of acute bronchiolitis. Current Paediatrics 1996;6:252-6.

4 Lugo RA Nahta MC Pathogenesis and treatment of bron chiolitis. Clin Pharmacokinet 1993;12:95-116.

5 McConnochie KM, Roghmann KJ. Wheezing at 8 and 13 years: changing importance of bronchiolitis and passive smoking. Pediatr Pulmonol 1989;6:138-46.

6 Wang EEL, Law BJ, Stephens D, et al. Pediatric investigators collaborative network on infections in Canada: prospective study of risk factors and outcomes in patients hospitalized with repiratory syncytial viral lower respiratory tract infection. F Pediatr 1995;126:212-19.

7 Walsh EE, McConnochie KM, Long CE, et al. Severity of RSV infection is related to virus strain. $\mathcal{F}$ Infect Dis 1997; 175:814-20.

8 Hall CB. RSV. In: Feigen RD, Cherry JB, eds. Textbook of . pediatric infectious disea

9 Isaac D. Bronchiolitis [editorial] BMF 1995;310:4-5.

10 Simpson H. Respiratory syncytial virus infection. Med Interna 1992;105:4418-20.

11 Phelan PD, Landau LI, Olinsky A. Respiratory illness in children, 3rd ed. Oxford: Blackwell Science Publications, 1991: $66-73$.

12 Sterner G, Wolontis S, Bloth B, et al. RSV. An outbreak of acute respiratory illness in a home for infants. Acta Paediat Scand 1966;55:273-9.

13 Berman S, Shanks MB, Oeiten D, et al. Acute respiratory infections during the first three months of life. Pediat Emerg Care 1990;6:179-82.

14 Mulholland EK, Olinsky A, Shamm FA. Clinical finding and severity of acute bronchiolitis. Lancet 1990;338:125961 .

15 Barry W, Cockburn F, Price JF, et al. Ribavirin aerosol for acute bronchiolitis. Arch Dis Child 1986;61:593-7.

16 McIntosh EDG, De Silva LM, Oates RK. Clinical severity of RSV group A and B infection in Sydney, Australia. Pediatr Infect Dis ₹ 1993;12:815-19.

17 Van Woensel JOB, Wolfs TFW, van Aalderen WMC, et al. Randomised double placebo controlled trial of predRandomised double placebo controlled trial of predbronchilitis. Thorax 1997;52:634-7.
18 Wang EEL, Law BJ, Boucher FD, et al. Pediatric investigators collaborative study on infections in Canada (PICNIC)
study of admission and management variation in patients study of admission and management variation in patients hospitalized with respiratory syncytial viral lowe

19 Rakshi K, Couriel JM. Management of acute bronchiolitis. Arch Dis Child 1994;71:463-9.

20 Brandenburg AH, Jeannet PY, Steensel-Moll HA, et al Local variability in respiratory syncytial virus disease severiry. Arch Dis Child 1997;77:410-14.

21 Ray CG, Minnich LL, Holberg CJ, et al. Respiratory syncytial virus-associated lower respiratory illnesses: possible influence of other agents. The group health medical associates. Pediatr Infect Dis f 1993;12:15-19.

22 Tristram DA, Miller RW, McMillan JA, et al. Simultaneous infection with respiratory syncytial virus and other respiratory pathogens. Am 7 Dis Child 1988;142:834-6.

23 El-Radhi AS, Rostila T, Vesicari T. Association of high fever and short bacterial excretion after salmonellosis. Arch Dis Child 1992;67:531-2.

24 El-Radhi AS, Banajeh S. Effect of fever on recurrence rate of febrile convulsion. Arch Dis Child 1989;64:869-70.

25 El-Radhi AS, Carroll J. Fever and hypothermia. In: Fever in paediatric practice. Oxford: Blackwell Scientific Publications, 1994:19.

26 O'Dempsey TJD, Laurence BE, McArdle TF, et al. The effect of temperature reduction on respiratory rate in febrile illnesses. Arch Dis Child 1993;68:492-5.

27 Shaw KN, Bell LM, Sherman NH. Outpatient assessment of infants with bronchiolitis. Am F Dis Child 1991;145:1515.

28 Dawson KP, Long A, Kennedy J, et al. The chest radiograph in acute bronchiolitis. $\mathcal{F}$ Paediatr Child Health 1990;26:20911.

29 Outwater KM, Crone RK. Management of respiratory failure in infants with acute viral bronchiolitis. Am $\mathcal{F}$ Dis Child 1984;138:1071-5

30 Issacs D. Production of interferon in respiratory syncychial virus bronchiolitis. Arch Dis Child 1989;64:92-5.

31 Fleming PJ, Howell T, Clements M, et al. Thermal balance and metabolic rate during upper respiratory tract infection in infants. Arch Dis Child 1994;70:187-91. 